\title{
Heat Transfer Enhancement by Coated Surface: A Review Study
}

\author{
Muhammad Afaz Uddin ${ }^{1 *}$, Md. Aminul Islam², Mohammad Zoynal Abedin ${ }^{3}$ \\ ${ }^{I}$ Department of Mechanical Engineering, Dhaka University of Engineering \& Technology, Gazipur-1707, \\ Bangladesh \\ ${ }^{2}$ Mechanical Engineering, Dhaka University of Engineering \& Technology, Gazipur-
}

1707, Bangladesh

${ }^{3}$ Department of Mechanical Engineering, Dhaka University of Engineering \& Technology, Gazipur-1707, Bangladesh

\author{
*Corresponding Author: Muhammad Afaz Uddin, Department of Mechanical Engineering, Dhaka \\ University of Engineering \& Technology, Gazipur-1707, Bangladesh
}

\begin{abstract}
The heat exchanger has the prime role in the heat transfer processes such as energy storage and recovery. For increasing the performance of the heat exchanger, the heat transfer enhancement methods are utilized in many commercial and industrial application. The heat transfer methods are widely used in areas such as thermal power plants, air conditioning equipment automobile, and aerospace. These methods are classified into three categories a) Active methods b) Passive methods c) Compound methods. The main goal might be to reduce the heat exchanger size or pumping power required for a specified heat duty, and also to protect excessive temperature, or even system destruction, in systems where heat generation rates are fixed, as for example, in nuclear fuel assemblies or in chemical reactors. Numerous enhanced surfaces have been developed to intensify flow as well as pool boiling heat transfer. Now a days, the passive methods has been more useful to designers to enhancement the heat transfer in heat exchanger. This types of augmentation methods does not use any external power input. One of the ways to enhance heat transfer performance in passive method is to increase the effective surface area and residence time of the heat transfer fluid. Factories have demanded for more efficient boilers and evaporators as well as economic incentives have motivated the development of methods to increase boiling heat transfer coefficients, critical heat fluxes, and where possible, to obtain the highest heat flux by applying the smallest wall superheat.
\end{abstract}

Keywords: Porous coatings; Heat exchanger; Film wise condensation; steam condensation, surface tension

\section{INTRODUCTION}

Heat exchange process has involved with the conversion, utilization, and recovery of energy in every industrial, commercial, and domestic applications. The common examples are steam generation and condensation in power and cogeneration plants; sensible heating and cooling of viscous media in thermal processing of agricultural products, chemicals and pharmaceuticals; refrigerant evaporation and condensation in air conditioning and refrigeration; gas flow heating in manufacturing and waste-heat recovery; air and liquid cooling of engine and turbo machinery systems; and cooling of electrical machines and electronic devices. Over and above that in the usual or standard practice, can significantly improve the thermal efficiency in such applications as well as the economics of their design and operation.

The engineering cognizance required to increase the thermal performance of heat exchangers, thereby effecting energy. Cost and material savings as well as a consequential reduction of environmental dilapidation had led to the development and use many types of heat transfer enhancement techniques. These techniques have in the past been referred to variously as augmentation and intensification, among other stages.

\section{DISCUSSION}

An impressive list of information is available in relevant references for coating surfaces. Many researchers have performed theoretically and experimentally analysis in this type of treated surface. From the available literatures, the major contributions of researchers are as follows: Thomas Young 
[1] proposed treating the contact angle of a liquid with a surface as the mechanical equilibrium of a drop resting on a plane solid surface under the restrains of three surface tensions: $\gamma_{\mathrm{LG}}$ (at the interface of the liquid and vapor phases), $\gamma_{\mathrm{SL}}$ (at the interface of the solid and liquid phases) and $\gamma_{\mathrm{SG}}$ (at the interface of the solid and vapor phase). This lead to Young's equation: $\gamma_{\mathrm{SG}}-\gamma_{\mathrm{SL}}=\gamma_{\mathrm{LG}} \cos \theta$.This equation is deceptively simple, but there are a few difficulties with it because of the definitions of the surface tension of the solid-vapor and solid liquid phases. Another approach avoids specifying the field of intermolecular forces between solid and liquid and instead offers a thermodynamic solution. This lead to Young and Dupre' equation which introduces the reversible work of adhesion of liquid and solid and it's relation to the surface tension between liquid and vapor phases and the contact angle:WA $=\gamma_{\mathrm{lv}}(1-\cos \theta)$ Where, WA is the reversible work of adhesion of the liquid to the solid when coated with an adsorbed film of the saturated vapor. A wetting liquid is a liquid that forms a contact angle with the solid which is smaller than $90^{\circ}$. A non-wetting liquid creates a contact angle between $90^{\circ}$ and $180^{\circ}$ with the solid.

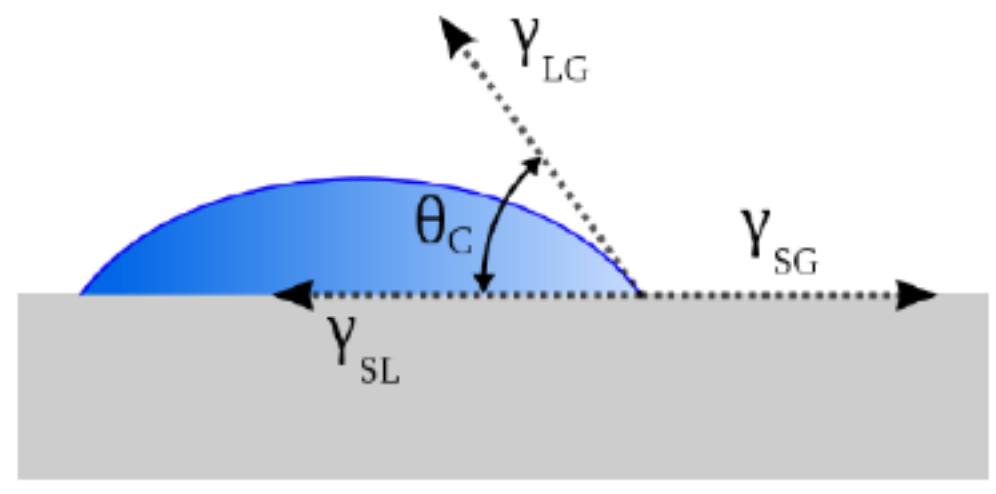

Figure1. Contact action for the wetting of a surface

According to Brown and Matin [2] the enhancement is dependent on the liquid contact angle and the thermal conductivity of the base surface.

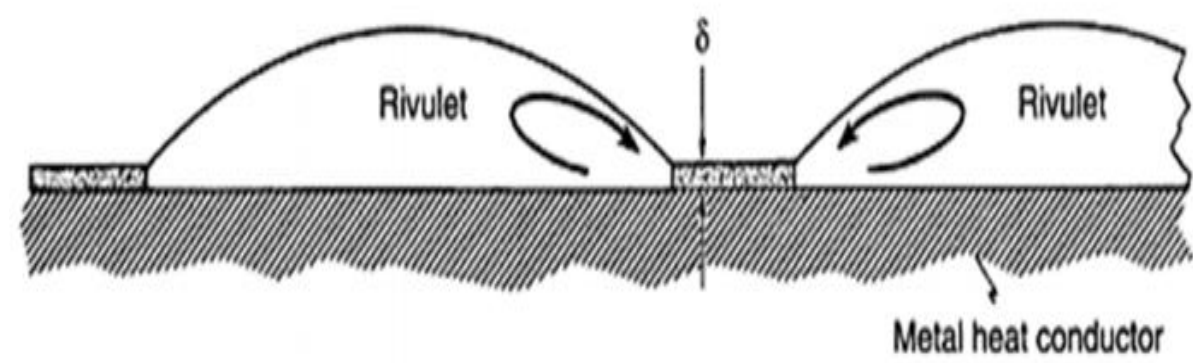

Figure2. Cross section of a vertical condensing surface on which nonwetting strips are attached.

Cary and Mikic [2] reason that an additional enhancement mechanism will be present due to a tension induced secondary flow. They have showed that the liquid surface temperature will be reduced near the nonwetting strip, resulting in a surface tension gradient causing the secondary flow.

Glickman et al. [2] measured the effect of nonwetting teflon strips for steam condensing on a horizontal tube. The helically wrapped $3.2 \mathrm{~mm}$-wide, $0.16 \mathrm{~mm}$-thick tape on a $12.7 \mathrm{~mm}$-diameter copper tube and tested two strip spacings : $p / d_{0}=3$ and 6 . The $p / d_{0}=3$ wrap gave a $35 \%$, increased condensation coefficient. However, greater enhancement was with a simple axial the strip along the bottom of the tube. This yielded a 50\%, enhancement level. Addition of the helical Wrap with the bottom axial tape strip did not provide further enhancement.

A U.S. patent by Notaro [2] describes a coated surface geometry for enhanced film condensation. It consists of an array of small-diameter metal particles bonded to the tube surface. The particles are 0.25 to $1.0 \mathrm{~mm}$ high covering 20 to $60 \%$ of the tube surface. 


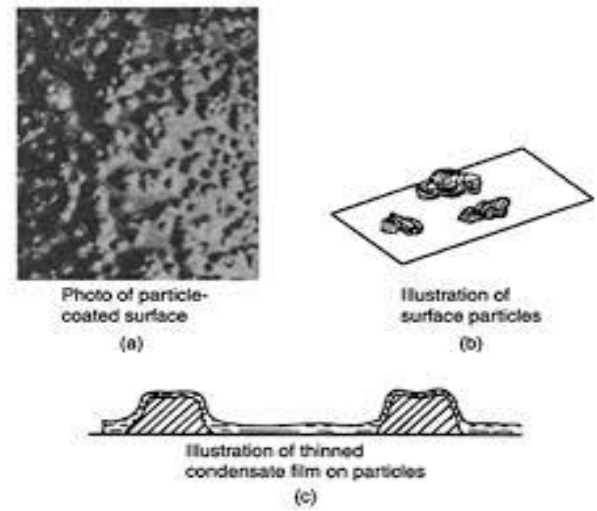

Figure3. Enhanced condensation surface formed by small diameter metal particles bonded to the base surface, (a) Actual surface, (b) particles bonded to surface, (c) thin condensate film on particles and thick condensate film on base surface.

For the film condensation a porous coating on the base surface can be a very effective enhancement method. Condensate drainage is helped by capillary flow within the porous coating, resulting in a thinning of the condensate film thickness. Because the temperature drop across a laminar condensate film is the condensation thermal resistance, such capillary-assisted film thinning is effective in reducing the condensate thermal resistance. For laminar condensation film on an uncoated plate, for which the

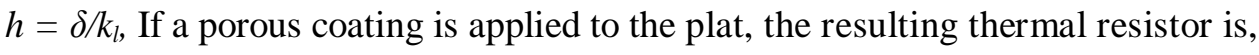

$h=e / k_{p, e},+\delta_{\text {mod }} l k_{l}$, where the first term is the thermal resistance of the porous film of thickness $e$ and effective Themal conductivity $\mathrm{k}_{p, e}$, The $\delta_{\text {mod }}$ is the reduced film thickness resulting from condensate suction into the porous coating and $k_{p, e}$ is the effective thermal conductivity of the liquid saturated porous coating. The enhancement ratio $\left(\mathrm{E}_{0}\right)$ is,

$\mathrm{E}_{0}=\frac{e / k_{p, e} e^{+} \delta_{\text {mod }} / k_{l}}{\delta / k_{l}}$

Ma and Wang [2] have performed analytical analysis of steam condensation on a vertical plate having a thin porous coating. Their analysis provides the solution for $\delta_{\text {mod }}$, which depent on the suction velocity $\left(\mathrm{V}_{\mathrm{o}}\right)$ at the porous interface surface. The velocity $\mathrm{V}_{\mathrm{o}}$ is given by, $\mathrm{V}_{\mathrm{o}}=\frac{e u_{D}}{L \epsilon}$, where $u_{D}=\mathrm{K}\left(\rho_{\mathrm{i}}-\rho_{\mathrm{v}}\right) / \mu$, for which for which $u_{D}$ is the Darcy velocity (the mean velocity within the porous coating), $\in$ is the coating porosity, and $K$ is its permeability. The enhancement increases with increasing $V_{o}$, and increased coating thickness up to a coating thickness of $50 \mu \mathrm{m}$.

Renken and Aboyoe [3] and Renken and Mueller [2] obtained steam condensation on porous coated surfaces with coating thickness of $25 \mu \mathrm{m}$ to $250 \mu \mathrm{m}$ and porosity of approximately $50 \%$. Their steam condensation tests showed the highest enhancement was provided by the thinnest coating. Renken and Raich [2] extended the measurements to include effects of forced convection steam.

Eric Forrest et al. [8] observed that critical heat flux (CHF) enhancement for all thin-film coatings tested. The enhancement ranged from $44 \%$ to $101 \%$ with the highest enhancement observed for the thickest, calcinated coating. CHF enhancement increases with the superhydrophilic thin-film coating thickness. Because the coatings were calcinated to form a nanoporous structure, this implies that the total pore volume may have an effect on the CHF, in addition to the apparent contact angle.

Janusz T. Cies 'in'ski [9] has proposed a correlation equation for heat transfer coefficient calculation during flow boiling of pure refrigerants inside a tube with porous coating. And the results for flow boiling of pure refrigerants and refrigerant/oil mixture inside porous coated tubes shown that application of a porous coating results in a higher, even five to six times, average heat transfer coefficient and simultaneously in lower pressure drop in comparison with smooth stainless-steel tubes for flow boiling of tested pure refrigerants R22, R134a, and R407C

Ying Zheng et al. [12] have observed that porous coating surface with Self-Assembled Monolayer (SAM) coating can further increase the condensation heat transfer coefficient for drop wise condensation and also porous coated surface without a SAM coating exhibited a surprisingly high 
heat transfer coefficient for film wise condensation mode. They have found that about 5 times heat transfer improvement when applying the SAM coating at vapor temperature around $50^{\circ} \mathrm{C}$.On the porous coated surface condition, additional 20\% improvement of heat transfer coefficient is achieved under the same heat flux or vapor temperature conditions.

Ying Zheng et al. [13] have measured the enhanced heat transfer for the steam condensation on the surface with sintered powder. The two powder sizes, $250 \mu \mathrm{m}$ and $63 \mu \mathrm{m}$ have been chosen to be sintered on the copper surface to examine the heat transfer enhancement, as well as the effect of powder size on the extent of condensation heat transfer improvement, the surface with $63 \mu \mathrm{m}$ has shown an approximately 20\% increase in heat transfer enhancement on film wise condensation compared to plain surface, with $250 \mu \mathrm{m}$ shows a significant more than twice heat transfer performance.

Anton Surtaev et al. [14] have concluded that for the capillary-porous coatings with the thickness of more than $800 \mu \mathrm{m}$ in the region of low heat fluxes $\left(\mathrm{q}<5 \mathrm{~W} / \mathrm{cm}^{2}\right)$ is observed the maximum heat transfer enhancement at liquid nitrogen boiling (by the factor of $1.5-4$ ). And the mechanism of enhancement

heat transfer for three-dimensional capillary-porous (TCP) coatings is raised in the share of heat transferred by intensive evaporation of numerous liquid during the formation and departure of large-scale vapor conglomerates. Water boiling on the capillary-porous coatings with the thickness of less or about $800 \mu \mathrm{m}$ changes heat transfer enhancement from the mechanism proposed for describing the results obtained at liquid nitrogen boiling.

\section{CONCLUSION}

In this review paper we have investigated to show the prospects of using the new types of capillaryporous coatings for enhancement of heat transfer for coolants with different physical properties. In the meantime, in order to gain a deeper understanding of the effect of different morphological parameters of capillary-porous coatings such as thickness and porosity of the coatings, powder material, the channel sizes, etc. On heat transfer and local characteristics at boiling of various liquids, the more detailed analysis of high-speed visualization data and further research are required. Heat transfer enhancement can discord substantially depending on the properties of liquid and morphology of coatings. The enhancement factor for the developed capillary-porous coatings is compared with the results of previous studies obtained using the structured surfaces with re-entrant cavities, micro channels and coatings fabricated by the gas thermal methods. It has been found that aluminum deposited onto the flat heating surface has an evident superiority over other tested materials i.e. copper, brass, molybdenum, and stainless steel. The probable reason is the very good metallic contact between the aluminum porous matrix and the substrate. Metallic porous coating has no impact on the burnout heat fluxes; the range of them was well predicted by the Kutateladze-Zuber as well as Haramura-Katto correlations. For certain porous coating parameters, strong hysteresis phenomena can be complied within the whole nucleate boiling regime. The main condition to enhance the heat transfer is to achieve the swirl in the bulk of fluids this can be done by the passive heat transfer enhancement methods. The heat enhancement methods have the easy installation and removal as well as simple manufacturing process with low cost. We know that the heat transfer enhancement can be done by inserts such as wire coils, twisted tube which are easily available and the process is simple. Because of the above some reasons the passive heat transfer enhancement methods are widely used in the commercial and industrial applications. The passive heat transfer enhancement methods play the very vital role in improving the overall heat transfer coefficient of the heat exchanger.

\section{REFERENCES}

[1] Gould, R.F. 1964. Contact angle wettability and adhesion American Chemical Society, USA. Pages 1-4.

[2] Webb L.R, Nae-Hyun Kim, Principles of enhanced heat transfer, Taylor and Francis, Taylor and Francis group.

[3] Renken K. J, Aboye M. Analysis of film condensation within inclined thin porous-layer coated surfaces int. J. Heatand Fluid Flow, Vol. 14, No. 1, March 1993

[4] Adamson, A.W. and Gast A.P. 1997. Physical Chemistry of Surfaces. 6th ed. John Wiley \& Sons, NewYork. Pages 352-364.

[5] Renken, K. J. and Raich, M. R., 1996. Forced convection steam condensation experiments within thin porous coatings. Int. J. Heat Mass 39 (14), 2937-2945. doi:10.1016/0017-9310(95)00367-3 
[6] Renken, K.J., Raich, M.R. "Forced convection steam condensation experiments within porous coatings," Int. J. Heat Mass Tran., 39(14), pp.2937-2945, (1996).

[7] Seibold, A., Nardin, M., Schultz, J., Walliser, A. and Oppliger, M. 2000. Effect of dynamic contact angle on capillary rise phenomena. Colloids and Surfaces A: Physicochemical and Engineering Aspects, 161, 81-87.

[8] Forrest E., Williamson E, Buongiorno J, Lin-Wen Hu, Rubner M, Cohen R, Augmentation of nucleate boiling heat transfer and critical heat flux using nanoparticle thin-film coatings. International Journal of Heat and Mass Transfer 53 (2010) 58-67

[9] Janusz T. Cies'lin'ski, Flow and pool boiling on porous coated surfaces. Rev Chem Eng 27 (2011): 179190 @ 2011 by Walter de Gruyter Berlin Boston. DOI 10.1515/REVCE.2011.007

[10] Bonner, R., 2013. Advances in heat transfer through coatings and micro-scale features. PhD Dissertation, Lehig University.

[11] Bonner, R., Chen, C.H. and Zheng, Y., 2014. Enhanced dropwsie condensation for improved dry cooling efficiency. DOE SBIR Phase I Final Report, Award No. DE-SC0011317.

[12] Zheng Y, Chien-hua Chen, Pearlman H, Flannery M, Bonner R, Effect Of Porous Coating On Condensation Heat Transfer. 9th International Conference on Boiling and Condensation Heat Transfer April 26-30, 2015 - Boulder, Colorado

[13] Zheng Y, Chien-hua Chen, Pearlman H, Bonner R, Enhanced Filmwise Condensation With Thin Porous Coating, Proceedings of the First Pacific Rim Thermal Engineering Conference, PRTEC March 13-17, 2016, Hawaii's Big Island, USA

[14] Surtaev A, Kuznetsov D, Serdyukov V, Pavlenko A, Kalita V, Komlev D, Ivannikov A, Radyuk A, Structured capillary-porous coatings for enhancement of heat transfer at pool boiling. Applied Thermal Engineering 133(2018)532-542 https://doi.org/10.1016/j.app lthermaleng. 2018. 01.051

Citation: Muhammad Afaz Uddin, et.al, (2019)" Heat Transfer Enhancement by Coated Surface: A Review Study", International Journal of Modern Studies in Mechanical Engineering, 5(3), pp. 10-14. DOI: http://dx.doi. org/10.20431/2454-9711.0503002

Copyright: () 2019 Authors, This is an open-access article distributed under the terms of the Creative Commons Attribution License, which permits unrestricted use, distribution, and reproduction in any medium, provided the original author and source are credited. 